It will require a large experience to determine to what extent the practice we here adopted, is capable of superseding delivery by turning, in cases of placentia prævia generally. I am disposed to think that it is applicable in most cases of partial presentation, where the flooding has not been very great, and where it is not going on rapidly at the time when we are called in, provided the os uteri is dilatable; but where we cunnot afford to lose any time in sending for the apparatus, and where the discharge is so impetuous as to require checking absolutely and at once, the woman still being in a state capable of bearing the shock of delivery, the old practice is to be adopted without hesitation. We want facts also to show whether those cases where the placenta is planted so completely over the os uteri that the membranes caunot be felt, are as well suited to the galpunic treatinent as cases of partial presentation of the placenta, or indeed whether they are suited at all. With regard to the extreme cases of exhaustion from flooding where the woman is utterly incapable of sustaining the process of delivery, Mr. Kinder Wood's plan of detaching the entire placenta should be adopted, the liquor amnii having been first drawn off by Dr. Radford's stilette. When delivery is subsequently effected, the galvanism is very likely to be of service ; but as yet, I an not aware that it has been tried. Whilst on this subject I may perhaps be permitted to observe, that I think that the practice of detaching the placenta before delivery in cases of placenta provia has been advocated rather generally by Dr. Simpson, and that the consequence will he, that those who follow his advice, will lose, should I not say, destroy, a certain number of children that might have been saved on the old method. It is very probable, too, that the risk of uterine phlebitis may prove greater in forcible detachment of the entire placenta than in turning after detaching it partially."

- I cannot subscribe to the correctness of Dr. Simpson's views, in proposing this plan of practice where the os uteri is in ton rigid or undilatable a state to allow of turning, or where the cervix uteri is yet undeveloped, owing to the early period of pregnancy. I suspect that, under such circumstances, we should cause serious lacerations of these parts at the time, and such contusions as might anerwards lead to very grave consequences in the shape of hysteritis, uterine phlebitis, or hypertrophy and ulceration of the os uteri.

(To be continued.)

\section{CASE OF COMPOUND FRACTURE OF THE SKULL, WITH LOSS OF A PORTION OF} THE BRAIN.

By J. C. Parkgr, Esq., Surgeon to the Bridgewater Infirmary.

William Sinall, aged 27, was admitted into the Bridgewater Infirmary, under my care, on the 31 st of December last. He stated that he had fallen from a height of six or eight feet on a piece of iron, und had pitched on his head. On examination there was found a wound of the scalp about three inches in length, on the right side of the frontal bone, and about an inch above the frontal sinus. He complained of very little pain, had not been sick or giddy, and indeed had no symptom indicating fractured skull, much less wounded brain. On introducing my finger into the wound, I found the bone to a considerable extent was completely smashed. Huring first enlarged with the scalpel the external wound, I removed eight or ten pieces of bone; two were about an inch in diameter, others were very small; two or three had wounded the dura mater, and were driven into the substance of the brain, so that when removed they were covered with the inedullary substance. Having carefully removed every spicula as far as I knew, two sutures were inserted in the scalp at an interval of two inches, and water dressing was applied over the whole. The patient would not consent to be carried to the ward, but walked inmediately after the operation through a long passage, and up a flight of stairs, almost as if nothing particular had happened. He was put in bed, and ordered to be well purged with calomel ard colocyath, followed by a rhnbarb aperient.

On the following day, Jannary 1st, 1846, he had passed a tolerable night, bet had not wept; sinull portiuns of brain were exuding from the wound; there was slight erysipelatous inflammation around, and the eye of that side was closed; a quiet pulse, and no particular symptom worth recording. The oil-silk was ordered to be onitted froin the water dressing, and cold water and lint kept constantly applied. Ordered saline mixture, \&c.

It would be tedious to give the daily progress of the case, which by general treatment, according to the symptoms, progressed most favourably. The discharge of cerebral matter ceased after three or four days; the wound partly healed by the first intention; and partly by granulations; in six weeks he was made an outpatient, and he is now quite well, with the exception of a very trifling sore. The only inconvenience he complains of is, that on looking at any object it appears double.

The foregoing case is one which points out the necessity to the young practitioner of carefully examining every case, however slight it may appear. This man said he had nerely a cut on his head, and he had not the slightest symptom of any more serious injury; but following that very useful practice of inserting my little tinger into the wound, the case was immediately evident. Had it been neglected, the patient's life, there is little doubt, would have been sacrificed. During the progress of the case there were no pnrticular syinptoms connected with the nervous system manifested; nor were any phenomena tending to illustrate the doctrines of phrenology observed.

February 28, 1846. 